\title{
Comment on "Contributions of Anthropogenic and Natural Forcing to Recent Tropopause Height Changes"
}

Santer et al. (1) concluded that an observed increase in tropopause height from 1979 to 1999 resulted, in part, from tropospheric warming due to increased greenhouse gases. They further showed that the largest increases in tropopause height occurred towards the poles, particularly in the Southern Hemisphere, and asserted that this spatial pattern is significant.

Tropospheric warming can be characterized by an increase in the distance between upper-tropospheric pressure surfaces and a near-surface pressure level. This distance can be directly interpreted as the mean layer temperature, with warming of the $1000-300 \mathrm{hPa}$ layer resulting in a larger vertical separation between the two pressure surfaces (2). The globally averaged $300 \mathrm{hPa}$ surface, and other pressure surfaces, would also elevate if the global mean troposphere warmed. We agree with Santer et al. (1) that the use of quantities such as tropopause height, which represent an integral description of the atmosphere, may provide effective metrics to diagnose complex changes in atmospheric structure. For this reason, we conclude that pressure altitude and the thickness-derived temperature between pressure surfaces, such as the 300 $\mathrm{hPa}$ heights and the thickness temperature between the 1000-300 $\mathrm{hPa}$ pressure surfaces, provide effective alternative assessments of layer-averaged tropospheric temperatures.

Interannual variability in the $\mathrm{NCAR} /$ $\operatorname{NCEP}(3,4)$ reanalysis of the $1000-300 \mathrm{hPa}$ thickness temperature and the $300 \mathrm{hPa}$ heights over 1979-1999, using the same data as (1), are shown in Fig. 1, A and B. Trends are $0.032^{\circ} \mathrm{C} /$ decade $(P=0.65)$ in the layeraveraged temperature and $0.53 \mathrm{~m} /$ decade $(P=0.84)$ in the $300 \mathrm{hPa}$ height change. Globally-averaged tropospheric temperature trends are statistically indistinguishable from zero. Thus, the elevation of the globally averaged tropopause reported in (1) cannot be attributed to any detectable tropospheric warming over this time period.

Santer et al. (1) concluded that spatial patterns of tropospheric warming are significant. The NCAR/NCEP reanalysis of the $1000-300 \mathrm{hPa}$ average temperature trends over 1979-1999 and their zonal average are shown in Fig. 1, C and D. Santer et al. (1) found the largest increase in tropopause height in the high southern latitudes. This increase is clearly dominated by stratospheric changes [including atmospheric dynamics (5)], as there is broad tropospheric cooling in the Antarctic regions. Additionally, Fig. 1C shows little statistical significance $(90$ and 95\% levels are shaded). Therefore, in general, regional trends are statistically indistinguishable from zero and a tropospheric effect on tropopause height cannot be inferred.

Christy et al. (6) and Santer et al. (7) reported on a spurious lower stratospheric cooling in the NCAR/NCEP reanalysis data beginning in 1997. This coding might affect measures of tropospheric thickness temperature and height. This concern is unfounded
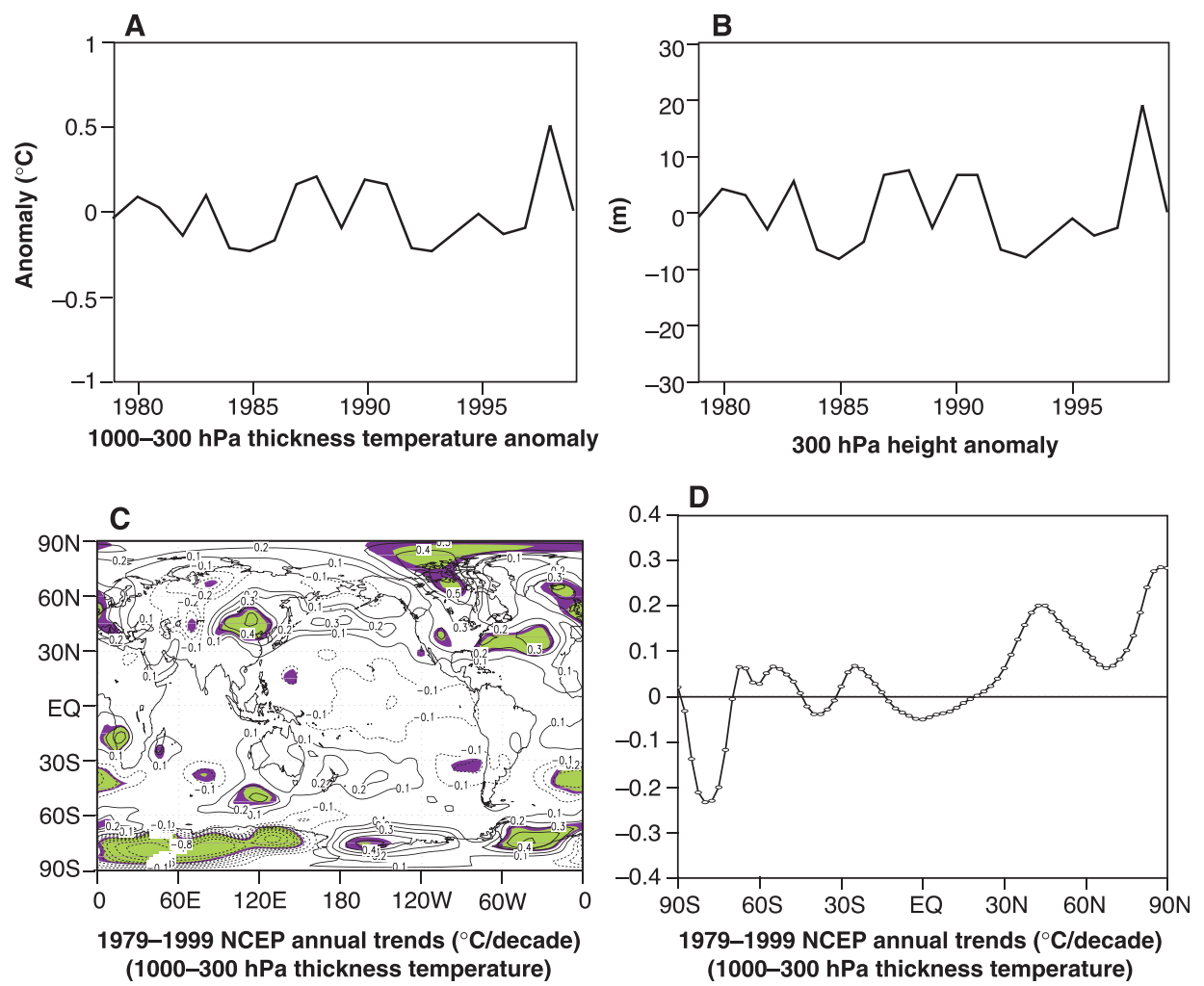

Fig. 1. Interannual variability in the NCAR/NCEP reanalysis of the 1000-300 hPa thickness temperature (A) and the $300 \mathrm{hPa}$ heights (B) over 1979-1999 using the same data as in (1). Bottom panels show the NCAR/NCEP reanalysis map of 1000-300 hPa thickness temperature spatial trends (C) and their zonal average (D) over 1979-1999. 

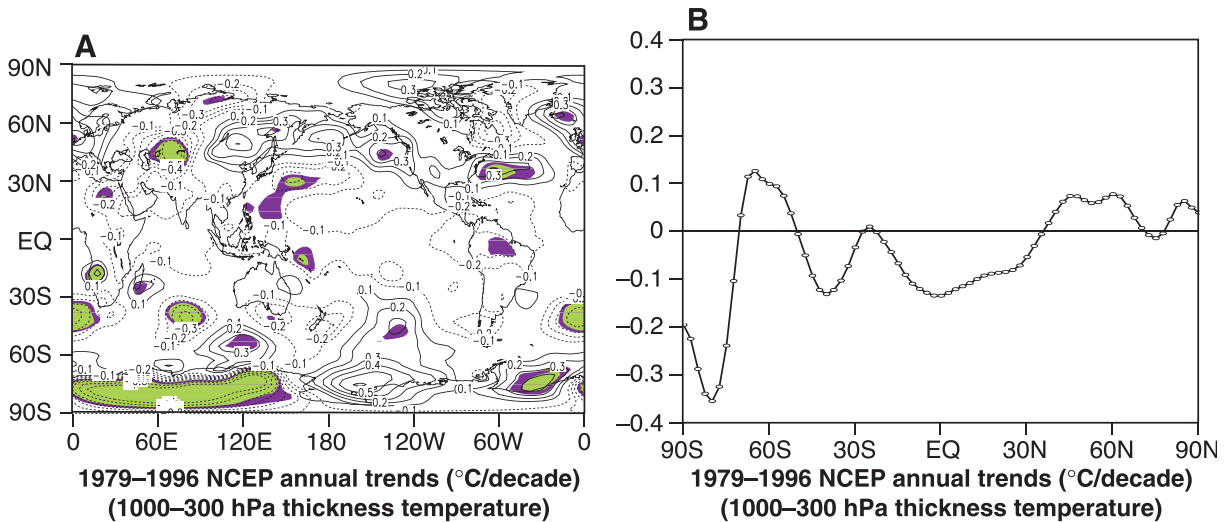

Fig. 2. NCAR/NCEP reanalysis map of 1000-300 hPa thickness temperature spatial trends (A) and their zonal average (B) over 1979-1996.

underlying tropospheric pressure-surface heights. Thus, the NCAR/NCEP reanalysis is a valuable tool for climate assessments $(9-12)$.

Some have questioned the independence of the NCAR/NCEP reanalysis and the MSU lower tropospheric data (13). However, our previous intercomparisons were made specifically with the Christy et al. (9) MSU lower tropospheric data (which was adjusted and merged with the microwave data sets), and not the raw MSU satellite radiances used in the package that generates temperature retrievals for NCEP reanalyses. The Christy et al. data product was not used in the NCAR/ NCEP reanalysis (6). Since the MSU lower tropospheric data and radiosonde data are independent sources, the long-term rate of change in the temperature fields that they diagnose are independent of each other. These data can therefore be compared to assess the accuracy of trend and variability in the reanalysis.
Observed changes in the magnitude of additional integrative measure of changes in tropospheric thermal structure where the atmosphere itself does the integration. Using the thermal wind equation, the eastwest wind velocity allows inference of the tropospheric-averaged, north-south horizontal temperature gradient (14). As shown in (14), there was no reduction in the equator-to-pole temperature gradient over 1979-1997 in either hemisphere, contrary to the indication in (1).

Finally, the climate system is much more complex than defined by tropospheric temperature and tropopause changes. Linear trend analysis is of limited significance (15). Changes in global heat storage provide a more appropriate metric to monitor global

Roger A. Pielke Sr. Department of Atmospheric Science the 200 (or 300 ) $\mathrm{hPa}$ winds provide an warming than temperature alone (16).
1371 Campus Delivery Colorado State University

Fort Collins, CO 80523, USA E-mail: pielke@atmos.colostate.edu

Thomas N. Chase Cooperative Institute for Research in Environmental Sciences (CIRES) and

Department of Geography

Campus Box 216

University of Colorado

Boulder, CO 80309, USA

\section{References and Notes}

1. B. D. Santer et al., Science 301, 479 (2003).

2. S. D. Gedzelman, The Science and Wonders of the Atmosphere (Wiley and Sons, New York, 1980), p. 535.

3. E. Kalnay et al., Bull. Am. Meteorol. Soc. 77, 437 (1996).

4. NCAR is the National Center for Atmospheric Research; NCEP is the National Center for Environmental Prediction.

5. P. Haynes, J. Scinocca, M. Greenslade, Geophys. Res. Lett. 28, 4179 (2001).

6. J. Christy, R. W. Spencer, W. B. Norris, W. D. Braswell, D. E. Parker, J. Atmos. Ocean. Tech. 20, 613 (2003).

7. B. D. Santer et al., J. Geophys. Res. 108, D1 (2003) (DOI 10.1029/2002JD002258).

8. E. Kalnay, personal communication.

9. J. R. Christy, R. W. Spencer, E. S. Lobl, J. Clim. 11, 2016 (1998).

10. R. A. Pielke, J. Eastman, T. N. Chase, J. Knaff, T. G. F. Kittel, J. Geophys. Res. 103, 16927 (1998).

11. R. A. Pielke, J. Eastman, T. N. Chase, J. Knaff, T. G. F. Kittel, J. Geophys. Res. 103, 28909 (1998).

12. T. N. Chase, R. A. Pielke, J. A. Knaff, T. G. F. Kittel, J. L. Eastman, Int. J. Climatol. 20, 503 (2000).

13. A. N. Basist, M. Chelliah, Bull. Am. Meteorol. Soc. 78, 1431 (1997).

14. R. A. Pielke Sr., T. N. Chase, T. G. F. Kittel, J. Knaff, J. Eastman, J. Geophys. Res. 106, D21, 27287 (2001).

15. J. Rial et al., Clim. Change, in press.

16. R. A. Pielke Sr., Bull. Am. Meteorol. Soc. 84, 331 (2003).

2 September 2003; accepted 16 November 2003 